\title{
Procesos de identificación nacional en población migrante: continuidades y quiebres en las relaciones intergeneracionales
}

\section{Processes of National Identification in Migrant Population: Continuities and Breakdowns in Intergenerational Relation}

\author{
Gabriela NOVARO \\ CONICET / Universidad de Buenos Aires (Argentina) \\ gabriela.novaro@gmail.com
}

Recibido: 21 de marzo de 2013

Aceptado: 18 de abril de 2014

\begin{abstract}
Resumen
Este trabajo procura contribuir al estudio de las migraciones, la educación y los procesos de identificación a partir de los avances realizados en una investigación en curso con población migrante boliviana que habita una localidad cercana a la Ciudad de Buenos Aires. En el artículo me centro en las expectativas educativas y las experiencias formativas de las familias y organizaciones sociales de un barrio y sus vínculos con las escuelas de la localidad. Abordo la forma en que los adultos transmiten a los niños simultáneamente el mandato de mantener a Bolivia como un fuerte referente de identificación y la expectativa de su inclusión a la nueva sociedad. Me detengo también en las experiencias escolares, señalando las tensiones entre los nuevos discursos de la interculturalidad, y el hecho de que los niños bolivianos e hijos de bolivianos son frecuentemente interpelados como extranjeros desde un discurso nacionalista tradicional, que incluye fuertes estereotipos sobre el país de origen de ellos y de sus padres.
\end{abstract}

Palabras clave: Migración; Niñez; Procesos de Identificación; Saberes; Escolarización.

\begin{abstract}
This work intends to contribute to the study of migrations, education and processess of identification, based on the developments of a research with migrant Bolivian population that lives in a locality near to the city of Buenos Aires. In the article I focus on the educational expectations and the formative experiences of families and associations of a neighborhood, and their bonds with local schools. I analyze the way in which adults transmit simultaneously the mandate of maintaining Bolivia as an important reference of identification and the expectation of their inclusion into the new society. I focus also in schooling experiences, pointing the tensions between the new discourses of inter-culturality, and the fact that Bolivian children, and sons and daughters of Bolivian parents are frequently understood as foreigners from a traditional nationalistic speech, which includes strong stereotypes about their original country.
\end{abstract}

Keywords: Migration; Childhood; Identity Processess; Knowledges; Schooling. 
Referencia normalizada: Novaro, G. (2014). Procesos de identificación nacional en población migrante: continuidades y quiebres en las relaciones intergeneracionales. Revista de Antropología Social, 23, pp. 157-179.

SUMARIO: 1. Introducción. 2. Migración boliviana en Argentina: representaciones sociales, patrones de asentamiento y desafíos de la nueva normativa. 3. Múltiples sujetos y tensiones locales: asociaciones, familias y escuelas de un barrio periurbano. 4. Identidades y memorias en pasado y en presente en contextos comunitarios y familiares 5. Identidades desafiadas: continuidades y quiebres en la transmisión intergeneracional. 6. Entre la legitimación-deslegitimación de memorias e identidades en la escuela. ¿La escuela boliviana como opción? 7. Reflexiones finales: los dilemas identitarios entre las familias y la escuela en contextos de diversidad y desigualdad. 8. Referencias bibliográficas.

\section{Introducción}

¿Desde qué modelos de identificación nacional se interpela a los niños y jóvenes migrantes en sus ámbitos familiares de referencia y en las escuelas argentinas?, ¿qué apropiaciones y rupturas se advierten en estos procesos en contextos de pobreza y en poblaciones - como la procedente de Bolivia en Buenos Aires- en las que las adscripciones nacionales coexisten de manera compleja con las identificaciones étnicas?, ¿qué expectativas familiares existen hacia la escuela en torno a la continuidaddiscontinuidad de las referencias nacionales de las jóvenes generaciones? ¿en qué lugar quedan ubicados los niños procedentes de Bolivia o hijos de padres bolivianos en tanto se apela a ellos como "hijos de...", "bolivianos de segunda generación"?

Intentando avanzar en torno a estas preguntas en una investigación en curso que comenzó en el año 2010 analizo la transmisión de referencias a Bolivia y el proceso migratorio entre inmigrantes procedentes de Bolivia que habitan un barrio cercano a Escobar, localidad ubicada $50 \mathrm{~km}$ al norte de la Ciudad de Buenos Aires ${ }^{1}$.

El trabajo de campo realizado desde una perspectiva etnográfica se centró hasta ahora en el contacto con dos organizaciones que nuclean a migrantes - la Colectividad Boliviana de Escobar y la Asociación de Mujeres Bolivianas de Escobar- y con numerosas familias. En particular con las mujeres de esta asociación y con algunos de sus hijos reconstruí narraciones biográficas buscando caracterizar recuerdos de su niñez, de las formas de crianza y de cómo los procesos migratorios atravesaron esas situaciones y sus hijos experimentaron estos procesos. Al mismo tiempo registré numerosos contextos de interacción: encuentros en las organizaciones de migrantes - fundamentalmente en la Asociación de mujeres durante el año 2012relaciones cotidianas familiares, vínculos de los padres con las escuelas de la zona, participación en festividades, etc. Durante el año 2013 profundicé los vínculos con una de las escuelas de la localidad, observé numerosas situaciones escolares y realicé entrevistas a distintos actores educativos de la localidad ${ }^{2}$.

${ }^{1}$ Esta investigación se desarrolla en el marco del Programa de Antropología y Educación, Facultad de Filosofía y Letras /Universidad de Buenos Aires, con el apoyo de esta universidad, el Conicet y la Agencia Nacional de Promoción Científica y Tecnológica.

${ }^{2}$ A diferencia de trabajos realizados anteriormente donde me centré en la escuela y desde allí procuré establecer relaciones con las familias, en este comencé haciendo una caracterización 
El análisis de estos registros ha permitido comenzar a reconstruir los procesos de transmisión de la memoria de la migración entre distintas generaciones. Esta reconstrucción se ha realizado atendiendo a la relación entre la transmisión de saberes y relatos y los procesos de identificación.

Considerando trabajos previos en el campo educativo ${ }^{3}$, pongo en relación la forma en que estos procesos se dan en ámbitos familiares y comunitarios con los discursos, mandatos y modelos de identificación que circulan en los espacios escolares. Concluyo el trabajo sistematizando las reflexiones fundamentales y planteando algunos desafíos que estas situaciones hacen evidentes tanto para el análisis como para la producción de propuestas de intervención en educación.

Con este recorrido se espera contribuir a la precisión de categorías y la profundización de debates que permitan comprender los procesos de identificación nacional y la relación entre las generaciones en situaciones de migración. A partir del registro de las complejidades de estos procesos y considerando el lugar estratégico de la escuela como productora de sujetos e identidades se plantea el desafío de desarrollar propuestas educativas que tengan un sentido de mayor igualdad al tiempo que reconozcan el componente diverso de la población.

\section{Migración boliviana en Argentina: representaciones sociales, patrones de asentamiento y desafíos de la nueva normativa}

Si bien este trabajo refleja particularmente la situación de una localidad de la provincia de Buenos Aires con alta proporción de población migrante, las problemáticas que se despliegan no pueden comprenderse fuera de las relaciones generales que caracterizan la situación de los migrantes latinoamericanos en Argentina ${ }^{4}$.

Diversos trabajos abordan la construcción de relatos acerca de la migración en Argentina señalando la contraposición entre la imagen de la migración europea de fines del siglo XIX y principios del XX como una oleada civilizatoria que aportó trabajo y cultura a la nación, y la imagen de los migrantes latinoamericanos como una invasión incivilizada que se asienta en el territorio apropiándose de espacios y empleos que no le corresponden. Esta polaridad en la valoración se sostiene en el desconocimiento de los procesos históricos que acompañaron ambas situaciones y en fuertes estereotipos expresados frecuentemente en clave racial (Pacecca y Courtis, 2008; Domenech, 2007).

profunda de la dinámica del barrio, me acerque a las organizaciones y familias, y luego comencé el contacto con las escuelas (donde continúo trabajando al día de hoy). Entiendo que este recorrido facilitó desmarcarme del lugar de docente con el que solía quedar identificada anteriormente, propiciando así un acercamiento de mayor confianza.

${ }^{3}$ Me refiero al trabajo desarrollado entre los años 2004 y 2009 siguiendo procesos de escolarización de niños migrantes bolivianos que asistían a instituciones educativas de la zona sur de la Ciudad de Buenos Aires. Como mencioné en la nota anterior, este trabajo se centró en instituciones escolares.

${ }^{4}$ En este sentido resulta sugerente la propuesta de abordar las migraciones considerando distintas escalas y la interrelación entre múltiples territorios y niveles - el local, el nacional, el transnacional- (García Castaño, Álvarez Veinguer y Rubio Gómez, 2011). 
La migración latinoamericana acompañó la conformación del estado nacional y se mantuvo relativamente constante a lo largo de la historia argentina — en cerca del 3\% de la población total—, con incrementos — sobre todo en la migración paraguaya y boliviana- en la década del 90. En las últimas décadas esta migración ha tendido a asentarse cada vez más en las áreas urbanas, cambiando un patrón previo de asentamiento estacional en las provincias fronterizas 5 . Asociado a estos cambios en los patrones de asentamiento y a la mayor permanencia se refuerzan los discursos xenófobos en general hacia la población latinoamericana y en particular hacia los bolivianos, con relación a los cuales se suelen incorporar más claramente elementos racistas en el discurso social, la prensa, los sindicatos argentinos, etc. (Pacecca y Courtis, 2008).

Las investigaciones señalan también su inserción al mercado de trabajo como pequeños cuentapropistas y como asalariados en sectores de mano de obra intensiva - en talleres de costura y en la producción hortícola periurbana - frecuentemente en situación irregular y de sobreexplotación. Se registra también la tendencia a la feminización de las migraciones limítrofes y al incremento en el componente de jóvenes.

Muchos autores hablan de la formación de barrios que parecieran funcionar como "enclaves bolivianos" facilitado por redes que encadenan contactos. Esta tendencia que algunos definen como "guetización" responde a la segregación espacial, la situación de discriminación en la nueva sociedad, la intención de fortalecer vínculos internos y mantener la continuidad de ciertas referencias identitarias nacionales, étnicas y regionales. Estos procesos terminan en lo que algunos denominan "terrorialización de la identidad" (Sassone y Mera, 2007; Grimson 1999; Gavazzo, 2011). En estas situaciones advertimos como el discurso nacionalista boliviano en ocasiones se articula con el discurso étnico, pero en ocasiones también invisibiliza y subordina el componente indígena de la población ${ }^{6}$.

Simultáneamente al proceso de territorialización y al reforzamiento de estereotipos en clave racial se registra un fuerte proceso de asociación de los migrantes que en gran medida se visibiliza en festividades, programas radiales, edición de periódicos, etc. Diversos especialistas se han detenido en las múltiples actividades que realizan estas asociaciones, a la vez que señalan la fragmentación, atomización y la crisis de representación que las caracteriza (Caggiano, 2005; Ortiz, 2005).

En los últimos años la situación de la población migrante latinoamericana en Argentina al menos en el plano legal se ha modificado por la sanción de una nueva

${ }^{5}$ Actualmente alrededor de la mitad de la población migrante boliviana reside en el Área Metropolitana de Buenos Aires y la región que bordea la ciudad de La Plata (capital de la provincia de Buenos Aires).

${ }^{6}$ La población procedente de Bolivia suma a las marcas de extranjería marcaciones étnicas vinculadas a cuestiones como la lengua - fundamentalmente el quechua - , las formas de agrupamiento, las festividades, etc. Las tensiones entre lo étnico y lo nacional adquieren particulares sentidos en contextos de migración. La importancia de estas tensiones se advierte además en la conformación del mismo estado "plurinacional" de Bolivia, donde la diversidad cultural es un criterio para reivindicar la existencia de naciones autónomas coexistiendo en relación a la misma formación estatal. 
normativa - ley 25.871/03 - sostenida formalmente en la noción de derechos -a la reunificación familiar, a la educación sin restricciones- - una perspectiva regional (Novick, 2008), como así también por la implementación de programas de regulación documentaria — como el "Patria Grande" — y los cambios en el panorama político de los países de origen.

\section{Múltiples sujetos y tensiones locales: asociaciones, familias y escuelas de un barrio periurbano}

El barrio donde trabajamos conocido como "El barrio boliviano" o "Villa bolita" se ubica a $3 \mathrm{~km}$ hacia el oeste del centro de Escobar'. Constituye un espacio fuertemente asociado a la producción y la comercialización fruti-hortícola habitado hasta mediados del siglo XX en gran medida por migrantes portugueses, italianos y japoneses. En la década del 60 comienza a llegar población desde Bolivia, fundamentalmente de zonas rurales del departamento de Potosí que generalmente se integra en el trabajo rural. En la década del 80 muchos de los migrantes bolivianos habían logrado cierta movilidad en la producción y comenzaron a adquirir terrenos propios (Benencia, 1997, 2008) y a insertarse cada vez más claramente en el circuito de comercialización. Junto con ello surgieron los intentos de formalizar una asociación ${ }^{10}$.

La Colectividad Boliviana de Escobar —en adelante la Colectividad-comenzó a organizarse desde el año 1986, si bien se institucionalizó en 1991. Reúne a unos 500 miembros y es propietaria de importantes edificios vinculados a la comercialización de productos frutihortícolas y de vestimenta. A diferencia de otras asociaciones de migrantes en ella es necesario ser socio para tener un puesto en los mercados. En trabajos previos, Cynthia Pizarro (2007) advierte el alto grado de institucionalización de esta organización, la forma en que alterna objetivos de integración a la sociedad nacional y de reforzamiento de identidades distintivas, la compleja coexistencia de propuestas de integración y aglutinamiento conjunto, mantenimiento de ciertas lealtades y opacamiento de situaciones de desigualdad.

La importancia de las festividades es significativa en la localidad, como así también el lugar de la colectividad como convocante y sostén; año a año el carnaval, el

${ }^{7}$ Patria Grande es un plan de regularización de inmigrantes lanzado por el presidente Néstor Kirchner en el año 2006. Está destinado a los ciudadanos nativos de países miembros del Mercosur y de los estados asociados al mismo (Bolivia, Brasil, Colombia, Chile, Ecuador, Paraguay, Perú, Uruguay y Venezuela). bolivianos.

${ }^{8}$ Bolita es un término utilizado en Argentina para referirse peyorativamente a los

${ }^{9}$ Escobar es uno de los 135 partidos de la provincia de Buenos Aires. En los últimos años se ha producido en esta localidad un gran crecimiento de población. Su cabecera es la localidad de Belén de Escobar ubicada $50 \mathrm{~km}$ al norte de la Ciudad de Buenos Aires.

${ }^{10}$ Trabajos previos de otros investigadores han permitido partir de una caracterización de la situación económica y de las organizaciones de la zona (Benencia, 1997; Pizarro, 2007; Dreidemie y Romani, 2007; Dreidemie, 2011, Daniel García, 2008). Estas últimas además facilitaron generosamente contactos con numerosas familias de la localidad. En particular quiero agradecer a Carla Romani y María María Kelly Trino Cazón por la compañía en los primeros años, la valiosa información sobre el barrio y el aporte de sus reflexiones. 
día de la independencia de Bolivia, el aniversario de Potosí entre otros son ocasión para la organización de multitudinarios eventos. Vinculando la relevancia de las festividades con la identificación nacional en la página de la Colectividad se afirma:

En lo cultural es permanente la presencia de la Colectividad en todos los actos, cívicos de homenaje a nuestra Patria Bolivia, cómo de la República Argentina, manteniendo latente la Identidad Boliviana, preservando las costumbres y tradiciones del solar patrio, trasuntada a través de sus grupos autóctonos de danza, música y otras manifestaciones culturales propias de nuestras raíces bolivianas (http://www. comunidadbol.com.ar, 2002).

En cuanto a la Asociación de Mujeres Bolivianas de Escobar —en adelante la Asociación-, la misma es una organización mucho más pequeña que formaliza su creación en el 2005. Nuclea particularmente a mujeres - aunque también participan hombres-, de condición humilde y en muchos casos con escasas experiencias escolares. Esta institución recupera y recrea formas de participación política de Bolivia, explícitamente buscando reproducir el modelo de los Centros de Madres - tipo de asociación muy extendida en ese país, vinculada a tareas de reproducción, emprendimientos productivos, reparto de comida, etc. ${ }^{11}$. En un marco de acciones muy variadas y dispersas, la asociación de mujeres funciona como un espacio convocante para actividades de promoción social y cultural, asistencia a las socias más pobres, asesoramiento sobre documentación, organización de eventos y un programa de radio y, sobre todo en los últimos años, gestión de diverso tipo de subsidios. Desde su origen se propone la apertura de una guardería - tarea que aún no ha concretado - y otras acciones dirigidas a la niñez. Vale aclarar que los contactos con las mujeres de esta asociación se hicieron mucho más frecuentes y cercanos a partir de responder al pedido de la presidenta de colaboración para organizar una propuesta de capacitación de adultos que, en sus propios términos "nos permita firmar, que nos ayude en los trámites, para que podamos ayudar a los hijos en la escuela y porque es una vergüenza que [en las elecciones, en los empadronamientos como no saben escribir su nombre] las mujeres anden metiendo los deditos en la tinta" (presidenta de la Asociación de Mujeres Bolivianas de Escobar).

La dinámica de la desigualdad y las lealtades locales, regionales y étnicas atraviesan estas organizaciones. La población boliviana del barrio a pesar de reconocer fuertes lazos de parentesco y paisanaje, hablar la lengua quechua en muchas

${ }^{11}$ Los Clubes de Madres son una forma organizativa muy común en Bolivia, registrándose hace algunos años cerca de 4000. Aparecen vinculados tanto a tareas de fortalecimiento del lugar de la mujer entre los sectores vulnerables, como a estrategias de asistencialismo, control y penetración del Estado, los organismos internacionales y la iglesia, especialmente a través de Caritas (González Guardiola, 2000; http://www.eurosur/org/Flacso/mujeres/Bolivia/org/htm). Algunas investigaciones en Bolivia sostienen que los clubes de madres asociados al avance de la modernidad en las zonas rurales contribuyeron en ciertas comunidades a crear una imagen materrnizada de las mujeres que desvalorizó sus saberes tradicionales en la producción pastoril y textil; de esta forma alteraron un sistema de relaciones de género previo en los Andes donde las mujeres tenían derechos públicos y familiares más equilibrados con los varones (Rivera, 2004). 
de sus interacciones cotidianas y proceder en gran medida de localidades cercanas de Potosí, lejos de homogénea, presenta una gran fragmentación entre propietarios de terrenos, comerciantes, medieros, arrendatarios, peones y pequeños comerciantes.

En esta situación la prédica del nacionalismo, la permanente alusión a Bolivia - sobre todo en las celebraciones de la Colectividad - puede asociarse tanto a la búsqueda de fortalecerse como colectivo en una situación adversa, como a la generación de una mística nacionalista que vele la desigualdad de las relaciones entre sectores connacionales y aborte la profundización de conflictos sociales entre los mismos inmigrantes ${ }^{12}$.

Diversos indicadores señalan también que estas organizaciones de migrantes están atravesadas por una lógica de género y que, si la Colectividad — cuyos cargos de dirección son ocupados casi totalmente por hombres- se asocia básicamente a tareas de producción y comercialización, la Asociación de mujeres se presenta fuertemente ligada a actividades de reproducción y socialización.

A la fragmentación, disociación y multiplicación de las experiencias de vida asociadas al traslado de zonas rurales a zonas urbanas o periurbanas y a la situación de migración internacional, se agregan las transformaciones que los sujetos perciben en la localidad en los últimos años entre un espacio centralmente asociado a la producción hortícola, y un espacio donde las actividades fundamentales se vinculan cada vez más a la comercialización de productos hortícolas y de productos industrializados, particularmente vestimenta ${ }^{13}$.

Vale destacar que durante los primeros años del 2000 y en el 2007 en el barrio se produjeron reiterados hechos de violencia y xenofobia con la población boliviana - secuestros, torturas, robos a quinteros-. Frente a estos hechos muchas versiones señalan que fueron las mujeres las que encabezaron denuncias y protestas. A propósito de éstas y otras múltiples situaciones se advierten procesos que podrían ser interpretados como de guetificación — materializado por ejemplo en el paulatino y constante crecimiento del muro que rodea los terrenos de la colectividad del barrio y

${ }^{12}$ La prédica nacionalista entre los migrantes bolivianos parece asociada a esta función encubridora sobre todo en el empleo en condiciones de explotación en los talleres por parte de patrones bolivianos vinculados desde un lugar subalterno con las grandes marcas de indumentaria (Pinto, 2008). En Escobar los sentimientos nacionalistas de la población boliviana se acentuaron en momentos de incremento de amenazas y violencia, en contextos de definiciones políticas en el país de origen, pero también en situaciones conflictivas que podrían dar cuenta de la estratificación interna (conflictos laborales en los mercados de fruta, tensiones por el alquiler y uso de puestos de venta de ropa, disputas por la obtencion y distribución de subsidios estatales, etc.). De cualquier manera, la asociación nacionalismo-explotación tampoco es lineal y se registra por ejemplo en la prensa boliviana y diversas organizaciones de migrantes el énfasis en resaltar cuestiones identitarias étnicas y nacionales, resistirse a la subalternización en el nuevo país, al tiempo que denunciar situaciones de explotación entre los mismos bolivianos.

${ }^{13}$ Un tema aparte, que no podemos abordar pero que sin duda está presente en este tránsito de muchos productores a comerciantes en la localidad (junto con otros condicionantes más estructurales), es la concepción sobre el comercio de la población boliviana de las zonas rurales. Lejos de una actividad que se vive como escindida de la producción, entre las familias campesinas de muchas zonas de Bolivia la venta directa es la culminación de una cadena productiva que asegura la continuidad de las actividades y mayores rentabilidades (Pinto, 2008: 32). 
en iniciativas como la construcción de un barrio cerrado "Cerro Rico", loteado mayormente entre población boliviana-y diversas y complejas formas de vinculación de la colectividad con el estado nacional y también con el estado boliviano.

La escuela aparece como un espacio donde esa articulación diversa y conflictiva con el estado se hace especialmente clara. En el barrio hay dos escuelas. Las vinculaciones de las familias y organizaciones con ellas parecen alternar entre la demanda mutua, la colaboración, el reclamo y la desconfianza. Muchos de los señalamientos a la escuela - sobre las formas de trabajo, la imagen de infancia, las relaciones escolares - resultan coherentes con un proyecto de la colectividad cuyo seguimiento es sumamente significativo con relación a nuestro tema de interés: la creación de una escuela "propia".

\section{Identidades y memorias en pasado y en presente en contextos comunita- rios y familiares}

Es necesario considerar la relación entre memoria, identidad y pertenencia en situaciones caracterizadas por la permanente transformación, la forma en que los procesos migratorios enmarcan la manera de representar el pasado, el condicionamiento de estos procesos por los dilemas de la situación actualmente vivida — de pobreza, desarraigo y significación de nuevos espacios y territorios-, los modos de interacción con el estado y con la escuela a propósito de los encuentros y desencuentros en los modelos de identificación.

En el barrio boliviano de Escobar se advierte la fuerza de las imágenes del país de origen - en discursos públicos, en festividades, en charlas informales - de referencias y narraciones sobre territorios y localidades en contextos de desterritorialización y reterritorialización, y de muy fuerte segregación socioterritorial en el país de destino.

En el caso de las organizaciones se comprende desde allí la constante puesta en acto de la doble pertenencia por ejemplo en las festividades; las recurrentes marchas con banderas argentinas y bolivianas hablan de esta vigencia de referencias a un lugar dejado y también de la apropiación de la simbología del que ahora se habita. En definitiva, se multiplica el despliegue de símbolos, iconos que marcan un territorio como propio, idealizan el espacio dejado y señalan la continuidad del pasado y las proyecciones en el nuevo espacio.

No solo las organizaciones, donde la institucionalización de la memoria y de las identidades seguramente colabora en la construccion de la misma con rasgos más fijos, sino también en los tránsitos cotidianos se despliegan en imágenes la posibilidad del encuentro y apropiación de un territorio nuevo. Así se advierte en las pinturas de los edificios, los nombres de muchos comercios - Kiosko "La Paz", remises "Sin fronteras", ómnibus "Potosi", "Odontología integral latinoamericana" las recurrentes alusiones al "allá" y el "acá".

Las referencias en presente al espacio dejado son también recurrentes en los relatos de migrantes. La sensación es que queda fijada e idealizada la imagen de Bolivia que corresponde a cuando los adultos se fueron — en muchos casos más de diez años 


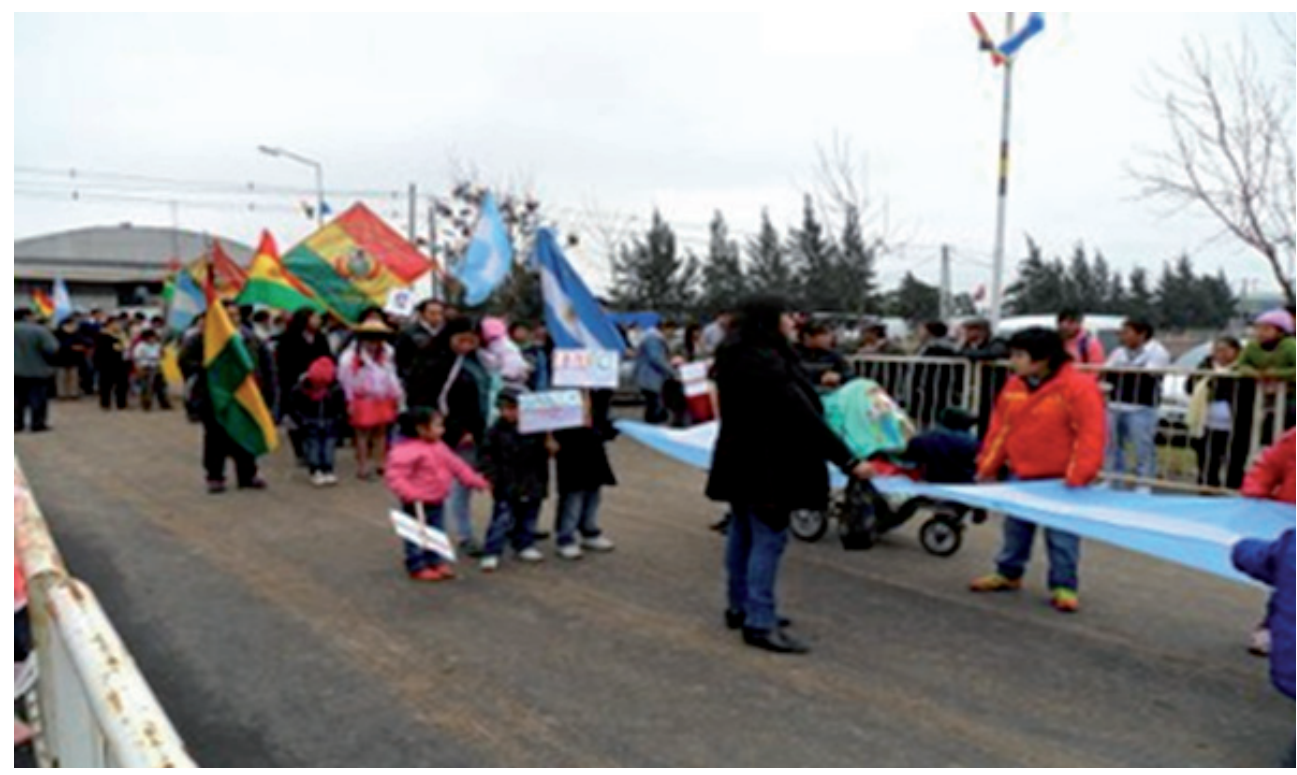

Imagen 1. Marcha con banderas argentinas y bolivianas en terrenos de la Colectividad Boliviana de Escobar el 6 de Agosto, día de la Independencia de Bolivia.

atrás-, cristalizada, detenida en el tiempo - las características de la escuela rural, los ritos, las prácticas de producción agrícola, la seguridad, la lengua, la disciplina escolar- . A partir de allí las alusiones al pasado se realizan frecuentemente en tiempo presente: "allá es diferente, es más ordenada" — la escuela—, "bueno, yo hace mucho que no voy... pero hasta ahora en Bolivia todavía hay ese respeto" (colaborador de la Asociación de Mujeres, migrante a la Argentina hace más de 40 años) ${ }^{14}$. Memoria actualizada para muchos en el permanente ir y venir de uno a otro país y en las múltiples redes tejidas entre Bolivia y Argentina. También memoria idealizada que se corresponde con una imagen de sujetos honestos, laboriosos, confiables ${ }^{15}$, que se estructura por contraste con estereotipos negativos instalados en Argentina sobre esta población: sumisos, dejados, pasivos, dependientes de los subsidios estatales.

La construcción de la identidad parece desplegarse en este contexto en relación a la tensión entre continuidad y cambio, asociado a representaciones sobre "lo boliviano" y "lo argentino" caracterizados a partir de atributos vinculados a la dualidad tradición-modernidad. Lejos de valoraciones fijas y constantes, junto con el deseo de inclusión en lo que se asocia a lo nuevo, se registra la nostalgia por la continuidad

${ }^{14}$ A este proceso parecen caberle en muchos sentidos las precisiones de Hobsbawn acerca de las tradiciones "inventadas" que en respuesta al incesante cambio del mundo moderno remiten a situaciones viejas intentando estructurar como inalterables algunas partes de la vida social (Hobsbawm, 1999).

${ }^{15}$ Vale aclarar que similares atributos positivos fueron sostenidos por ejemplo en el discurso de Evo Morales en su visita a Escobar donde destacó el carácter "trabajador, humilde, honrado del migrante boliviano en Argentina” (http://www.consulado boliviano.com.ar/portal/node/, 2011). 
y la tradición, la tranquilidad y la confianza atribuidos a Bolivia, que se opone a las imágenes de inseguridad y desconfianza vinculadas a Argentina.

La transmisión de la memoria además aparece obturada por recuerdos que muchas veces reviven el sentimiento de añoranza o remiten a situaciones de dolor y privación, vivencias que los sujetos al tiempo que no quieren recordar $-\mathrm{y}$ seguramente tampoco transmitir a sus hijos-, tampoco pueden olvidar, lo que nos habla de muchos silencios y muchos olvidos y también de una "selección de los recuerdos aceptables" (Candau, 2008). En este sentido muchos entrevistados se negaron a responder a la pregunta por la situación en Bolivia previa a la migración: "De eso no quiero hablar, me hace mal prefiero olvidar".

Frente a esta aparición y desaparición de las palabras que narran una historia y de silencios sobre esa historia, se busca transmitir la misma en gran medida por canales no necesariamente verbales: en actos - con gran evidencia en los festivos, despliegue de imágenes-, banderas, tramas vinculadas a las estéticas andinas, y también intentando dar continuidad a determinadas prácticas y saberes como la lengua quechua, la danza, el tejido, la cocina boliviana, la participación política en las organizaciones etc.

Candau, en términos sugerentes para comprender la situación registrada, se refiere a la pregnancia de los orígenes en la memoria social migrante que para facilitar la construcción de una identidad grupal se inclina por los símbolos posibles de reificación y por acentuar la permanencia de un supuesto origen, más aun en situaciones de frecuentes cuestionamientos a la identidad actual. Este autor caracteriza las memorias migrantes por la hábil conjugación de las incorporaciones y los rechazos de la novedad con la ideología de la conservación de la herencia. En cualquier caso, en la situación analizada, y en una lógica que articula constantemente el allá y el acá, es evidente siguiendo a Candau que la reconstrucción del pasado se realiza a partir de las necesidades del presente, de la imagen que se intenta construir del grupo con rasgos de continuidad en una situación de permanente cambio.

\section{Identidades desafiadas: continuidades y quiebres en la transmisión intergeneracional}

En definitiva, las prácticas y discursos registrados hablan de identificaciones producto en parte de la vivencia de integración y la distancia entre el origen y el destino y la búsqueda de significados del "allá" y el "acá".

¿De qué forma opera esto en la preocupación por la transmisión de referencias a las nuevas generaciones?

La conformación de un espacio como propio fuera del país de origen, las tensiones con la sociedad nacional, la experiencia de los permanentes cambios en este ámbito, las desiguales situaciones en que se encuentran los migrantes en la localidad tienen correspondencias más o menos claras con las preocupaciones de los adultos migrantes por la transmisión de la referencia a Bolivia en los niños nacidos en Bolivia que se han criado en Argentina y en los que muchos definen como "bolivianos de segunda generación" o "hijos de...". El sentido de esta categoría no es perma- 
nente ni unívoco. La misma se explicita tanto en las organizaciones como en las familias y también en las escuelas.

En las familias, se advierte estratégicamente la afirmación de la condición de "hijo de..." en determinadas situaciones, junto con discursos que destacan el carácter de argentinos de sus hijos frente a contextos de discriminación "porque van a discriminar si en la documentación es argentino" (comentaba en referencia a situaciones de discriminación vividas por sus nietos un hombre adulto boliviano, integrante de la Asociación).

Nos ha llamado particularmente la atención la importante capacidad de convocatoria entre los niños y jóvenes de algunas prácticas organizadas por la Colectividad que funcionan como fuertes marcantes de nacionalidad. Así, el fútbol parece ser un espacio de gran contención de los recién llegados, de convocatoria clara y sostenida a las nuevas generaciones; el fútbol, recreando una práctica de fuerte convocatoria "acá" y "allá" se presenta como espacio en el que los jóvenes bolivianos o "hijos de bolivianos" viven y muestran portando la camiseta verde de la selección boliviana, su relación con este país, fuera de él.

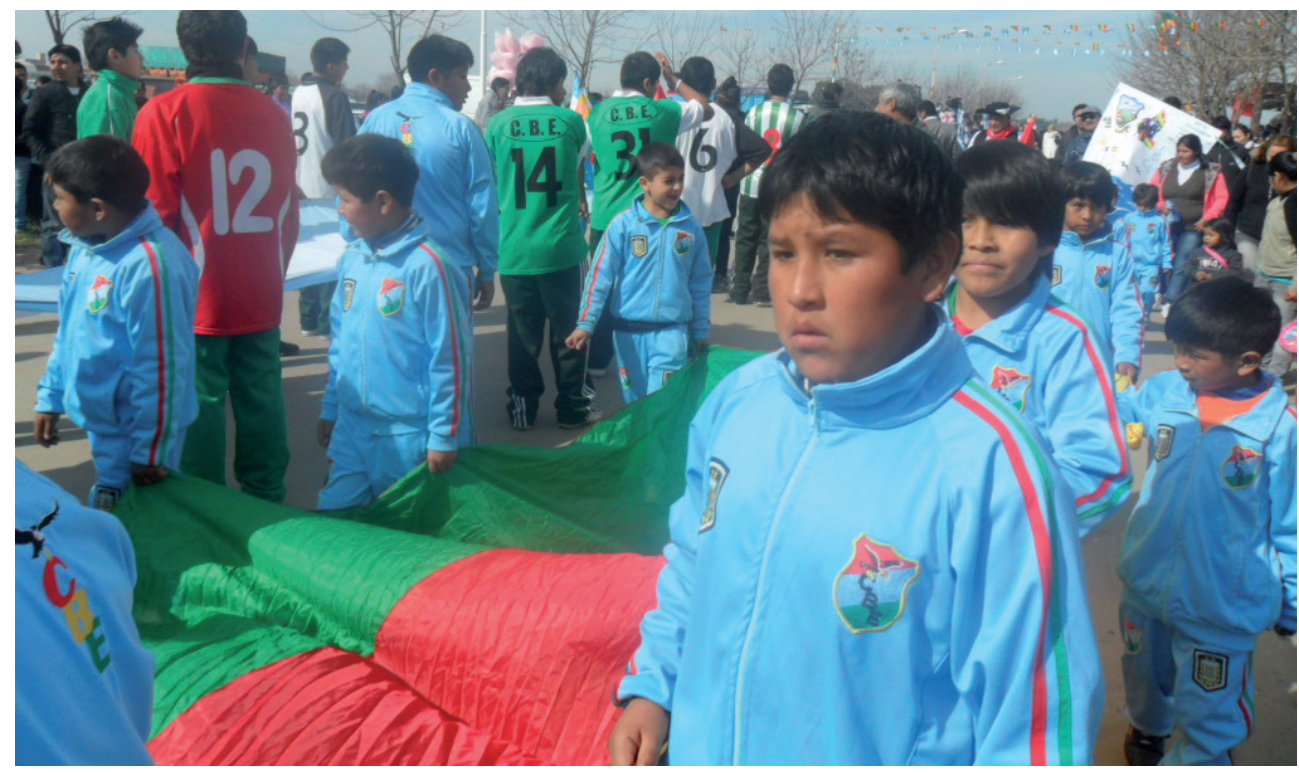

Imagen 2. Niños con el buzo de la Colectividad Boliviana portando una bandera de Bolivia; más atrás, jóvenes con la camiseta de la selección boliviana de fútbol.

Pero más allá de la capacidad de convocatoria de los jóvenes a las prácticas deportivas y festivas, los adultos se preguntan permanentemente por las referencias de identificación que efectivamente operan en ellos, advierten que sus hijos están interpelados por múltiples discursos y referencias, señalan su incertidumbre sobre el posicionamiento de las nuevas generaciones. La preocupación por la discontinuidad en 
las referencias de identificación se expresa en múltiples prácticas y discursos. Presentando un balance de las acciones deportivas se alude al interés por los niños "Apostamos a nuestra niñez, a nuestros hijos, que son ellos los que mañana estén al mando de nuestra institución" (http://www.comunidadbol.com.ar, 2002). Durante el 2012 se discutió el proyecto de asociación masivo de niños de más de 10 años como socios cadetes "porque estos chicos están en la suya, son muy individualistas, no les importa nada, no participan en lo colectivo... nosotros allá desde la pobreza compartíamos todo, ahora no es así" (inmigrante boliviano de La Paz, socio activo de la Colectividad). Resulta también significativa la relativa ausencia de jóvenes en la asociación de mujeres y que en parte a partir de esto su presidenta amenace permanentemente con la discontinuidad "yo me voy a Bolivia y ya no vuelvo... yo luché tanto por esto, por la personería jurídica, y ¿a quién voy a dejar?, quien va a continuar eso, yo no quiero que se pierda". Frente a esto por ejemplo los jóvenes vinculados a esta asociación reiteraron numerosas veces ante el pedido de mayor involucramiento que realizaba la presidenta: "yo doy una mano, pero no me comprometo $100 \%$, tengo mis estudios".

En los diálogos con las familias — particularmente con las mujeres y sus hijosy el registro de situaciones de interacción cotidiana, advertimos junto con la fuerte apuesta por la inclusión a la sociedad argentina, el señalamiento de su distinción como colectivo y el modo en que estas tensiones están presentes en las imágenes sobre sus hijos. Así, registramos reiteradamente la proyección a los niños de videos sobre bailes y programas televisivos de Bolivia y Perú, la apuesta por el carácter revelador que podría tener un viaje a Bolivia entre los hijos de bolivianos, "cuando vayan van a entender", al tiempo que se registran los quiebres y discontinuidades en las experiencias de distintas generaciones, "Yo me vine por motivo de ver a mi hija y ella no quería irse y ahora voy y vengo", "cuando estás allá te querés volver enseguida", "de vivir allí mis hijos no quieren saber nada, a pasear no más van", "quedarse allá, yo no creo que mis hijos lo aguanten" (comentarios de mujeres de la Asociación).

En las prácticas comunicativas se advierte la fuerza de la lengua quechua como marcante de identidad y mecanismo de reconocimiento en los adultos — por ejemplo en la Asociación las mujeres alternan el uso del quechua y el castellano permanentemente-, al tiempo que se registran muchos indicios de la retracción de la lengua aborigen entre los niños y jóvenes (Dreidemie, 2011).

Muchas familias afirman que la crianza de sus hijos fuera de Bolivia es determinante en términos de discontinuidades "mis hijos ya son así, ellos se han criado acá", "ya están acostumbrados, hicieron su vida" "de Bolivia no saben nada" (miembro activo de la Colectividad, padre de dos niños argentinos).

La preocupación por la transmisión de "una forma de ser" asociada a "lo boliviano" con atributos como respetuoso, trabajador, obediente, se fortalece en la representación del contacto con argentinos como contaminante y potencial fuente de contagio de prácticas como el robo, las drogas, el alcohol. "Cuando crezca quiero que se vaya a Bolivia, acá los chicos se echan a perder" (miembro de la Colectividad, padre de una niña boliviana de once años), "tenemos problemas con los vecinos, es gente jodida, los chicos son muy hinchas, son descendientes de bolivianos, pero ya se han criado acá asi” (miembro de la comisión directiva de la Colectividad). 
Como decíamos, en el registro de festividades, encuentros de asociaciones, prácticas deportivas, hemos identificado la reiteración del término "bolivianos de segunda generación" y también "hijos de..." y sus múltiples y poco claras connotaciones semánticas. Mientras en los contextos escolares estas categorías suelen tener un sentido de marcación, en general en las familias y organizaciones, parecen asociadas a la preocupación porque las nuevas generaciones crezcan en las disposiciones que han heredado en términos de Manhein (1993), porque aprendan y se incorporen a prácticas que los definan como participantes plenos y miembros del grupo (Lave y Wenger, 2007), por garantizar los procesos de sucesión en el amplio sentido de la palabra. Hay que advertir que esto se da en un contexto donde sin duda los sujetos se plantean cotidianamente quienes serán sus hijos, junto con dilemas sobre su asentamiento definitivo o la vuelta al país de origen y donde las expectativas familiares asociadas a la migración - y también al retorno - resultan en muchos casos en sueños incumplidos.

La categoría "bolivianos de segunda generación" resulta sumamente significativa en torno a la problemática de la transmisión de la identidad a las nuevas generaciones. Nos preguntamos si la reiteración de las interpelaciones identitarias de la colectividad a los niños y jóvenes puede leerse como indicador de supuestos déficits en estas identidades "heredadas" y también si puede o no ser entendida como la biologización y naturalización de la relación entre generaciones y la herencia de un estigma (Gavazzo, 2011, 2012), como imposición de una pertenencia de los adultos sobre los jóvenes, o como proyección de una referencia de identificación a la que estos mismos niños y jóvenes se adscriben. Desde aquí entendemos que las complejas dinámicas de la localidad no pueden ser comprendidas sino agregando a la dimensión de desigualdad y género ya mencionadas, la dimensión generacional. A partir de allí es fundamental relevar como experimentan los procesos de identificación los hijos de inmigrantes e incluso los jóvenes migrantes criados en Argentina. Numerosos relatos hablan de estas perspectivas y de estas vidas cruzadas por múltiples interpelaciones. En respuesta a la pregunta sobre dónde imaginaba su futuro una joven contesta:

Y ahora estamos acá, como te digo... el pueblo donde estábamos..., ya no es como antes, la mayoría están... personas adultas, de tercera edad, porque... los hijos están la mayoría acá, todos por motivos de trabajo, porque allá no... no tenemos, por ahí si para... vivir, pero después para comprarte algo no... no tenes ingreso... tenes que salir a otro lado... Mi mamá no quiere volver, fue muy duro para ella, tiene una historia triste... estamos toda familia o parientes acá, nos visitamos, compartimos..., todos crecidos acá y... seguimos para adelante. Es muy difícil volver..., nuestra tumba esta acá... si nos quedamos... si no nos echan (joven nacida en Bolivia y criada en Argentina, hija de una socia de la Asociación de Mujeres, 2012).

\section{Entre la legitimación-deslegitimación de memorias e identidades en la es- cuela. ¿La escuela boliviana como opción?}

Las referencias de identificación comunitarias y familiares, más o menos estereotipadas, más o menos legítimas, más o menos visibles no son definitivamente las únicas que interpelan a niños y adultos en estos contextos. No pueden ser entendidas 
omitiendo los sentidos y formas de las identidades y memorias hegemónicas. Considerando a la memoria nacional como "la más legítima de las memorias" en términos de Pollak (1989) o al menos, como una forma legítima de la memoria, para pensar la relación entre relatos nacionales e identidades en tensión, la escuela reaparece en su fundacional papel de constructora de sujetos y legitimadora de relatos.

En otros trabajos centrados en diversas instituciones escolares hemos profundizado en cómo la escuela sigue interpelando muy fuertemente a los niños migrantes desde el discurso nacionalista y definiéndolos como extranjeros, y advertimos también la relevancia de la escuela como agencia socializadora de la población migrante considerando por ejemplo la masividad de la presencia de los niños bolivianos en ella (Novaro y Diez, 2012) ${ }^{16}$.

Advertimos que la exclusión educativa de la población procedente de Bolivia más que corresponder a una forma evidente y manifiesta - considerando su presencia en el sistema educativo primario-, se corresponde con particulares modos de estar dentro del mismo en lo que entendemos como formas de inclusión subordinada: tránsito por circuitos escolares de menor prestigio, desconocimiento de las trayectorias educativas previas de los niños, estereotipos de los docentes sobre la escolarización en Bolivia — paradójicamente muy valorada por las familias-, bajas expectativas de desempeño, silenciamiento de sus palabras, confrontación de estilos comunicativos (Novaro y Diez, 2012; Novaro, 2013).

Señalamos la coexistencia de paradigmas tradicionales de la nacionalidad —en muchos casos en sus versiones asimilacionistas y de fuerte estigmatización de los migrantes latinoamericanos - con nuevas retóricas de la inclusión y la interculturalidad. Desde estos nuevos discursos, muchas veces articulados con proyectos democratizadores, se desarrollan propuestas de reivindicación étnico-cultural. Estas propuestas suelen asumir una valorización de la diversidad, asociada a estrategias de hipervisibilización de las referencias identitarias a través del estilo folklórico y festivo, desde el cual se invocan los supuestos saberes y referencias tradicionales de estos grupos. Señalamos que estas situaciones de expresión de la diversidad sociocultural en las escuelas tienen un sentido paradójico: la afirmación de un saber particular queda asociado a la pertenencia a un colectivo que ha sido previamente desvalorizado y con el que los niños sostienen relaciones ambivalentes (Novaro, 2011).

De parte de los niños migrantes caracterizamos la tendencia a silenciar sus referencias de identificación étnicas y nacionales en contextos públicos y de interacción con niños "criollos", junto con manifestaciones de nostalgia y valoración e incluso idealización de su país de origen — generalmente explicitadas en situaciones más privadas - y las huellas que en ellos han dejado los procesos de movilidad y fragmentación de sus familias.

En Escobar hemos registrado algunas situaciones que permiten construir el panorama educativo del barrio. Este panorama constituye un marco que da sentido a las

${ }^{16}$ Prácticamente la totalidad de los niños procedentes de Bolivia de hasta 13 años de edad asisten a la escuela, aunque este porcentaje disminuye notablemente entre los jóvenes 14 y 24 años, que asisten en un 47,3\% a establecimientos educativos (Cerrutti, 2009). 


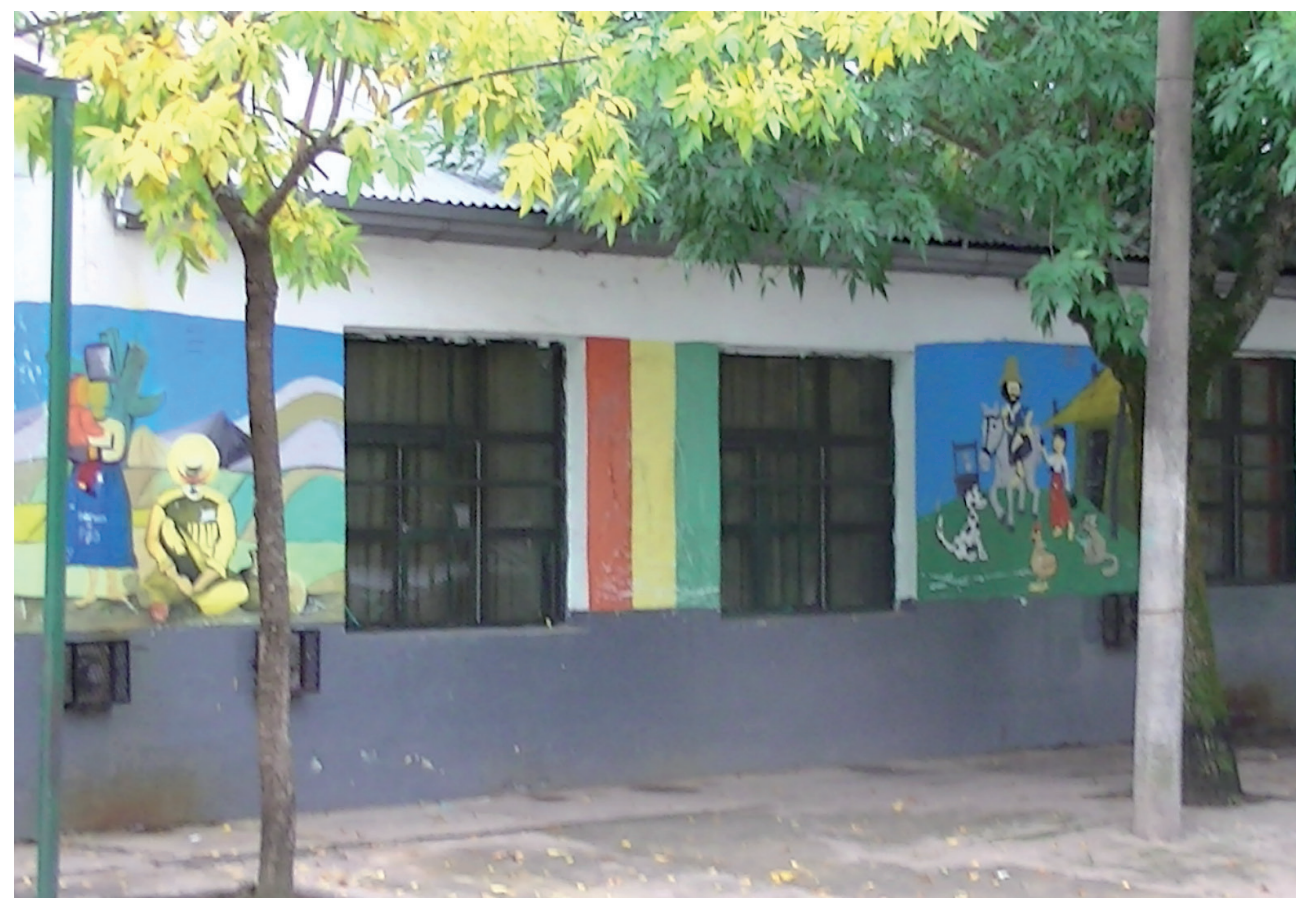

Imagen 3. Entrada de la escuela cercana a los terrenos de la Colectividad Boliviana de Escobar. Se destaca la imagen de una mujer con vestimenta típica de la zona andina, la bandera boliviana y el dibujo de un cabildo con el fondo celeste y blanco, (típica imagen de la historia escolar argentina).

tensiones identitarias entre el discurso escolar y las imágenes de niño y sujeto de las familias y organizaciones de migrantes ${ }^{17}$.

La dinámica escolar no está ajena a la fragmentación social del barrio y las tensiones locales, las que parecen tener cierto correlato en la elección de la escuela. Existen dos escuelas públicas, una a la entrada muy cerca de la ruta y otra en el medio del barrio y cerca de los mercados, las quintas y los terrenos de la Colectividad. En opinión de familias y representantes de la colectividad estas escuelas cuentan entre su matrícula con población en mejor y peor situación socioeconómica respectivamente y además, muchas familias propietarias o con empleos públicos estables optan por enviar a sus hijos a las escuelas privadas de Escobar.

Hemos registrado también escenas y discursos que remiten a las contradicciones y tensiones en las representaciones de los actores escolares sobre la población del barrio. Por un lado, se advierten situaciones y propuestas de acercamiento, encuentro y convocatoria, si bien desde imágenes y símbolos bastante estereotipados: las pinturas de la entrada de una de las escuelas — con la bandera argentina y boliviana,

${ }^{17}$ Vale aclarar que esta reconstrucción se sostiene básicamente en las representaciones de las familias y organizaciones sobre las escuelas, ya que los contactos con estas últimas todavía deben profundizarse. 
una mujer con vestimenta típica del altiplano y un gaucho-, el izamiento de dos banderas, la entonación del himno boliviano en algunos actos, etc.

Sin embargo, no es claro que esta aparente cercanía con la población migrante - aunque sea desde una iconografía tradicional - se traduzca en el cuestionamiento de concepciones educativas instaladas. En el discurso de algunos actores escolares, la pobreza y la diversidad de estos mismos migrantes se asocian a la carencia no solo material sino también cultural, y parece continuar habiendo grandes limitaciones para reconocer el valor educativo de las experiencias formativas de los niños que transcurren fuera de la escuela. Lejos de representar situaciones excepcionales, en otros trabajos advertimos cómo las imágenes sobre las experiencias formativas y sobre las posibilidades de aprendizaje se asocian a cuestiones muy difíciles de problematizar en la docencia. Junto con la preocupación por garantizar la presencia y la permanencia se expresan comentarios como "En la casa no tienen nada... Para ellos la escuela no es una prioridad, la prioridad de los bolivianos es juntar plata..., Los chicos acá hacen de chicos, son felices..., Cuando no están en la escuela los chicos trabajan, callejean, roban y se drogan" (registros en la escuela cercana a la Colectividad, 2010). El desconocimiento del valor formativo se extiende también a las apreciaciones sobre las escuelas en Bolivia — donde muchos chicos cursaron sus primeros años-, valoradas por muchos docentes argentinos como tradicionales, disciplinadoras y repetitivas. En trabajos previos (Diez y Novaro, 2014) hemos identificado estas mismas valoraciones en otras instituciones y el modo en que las mismas se sostienen en generalizaciones que desconocen las complejidades y el carácter heterogéneo y variable del sistema educativo boliviano.

En una visita reciente, un cartel de una de las escuelas condensaba lo que interpreté como parte de estas distancias y desencuentros. En la puerta se promocionaba un taller de lectura con la siguiente frase "La lectura mata... la ignorancia". En una localidad donde una alta proporción de la población adulta es analfabeta — cuestión que fuera advertida en charlas con el personal de la escuela, y en una institución donde se desarrollan actividades de terminalidad de primaria con adultos - cabe la pregunta sobre cómo leen los niños y adultos del barrio estos mensajes, dónde quedan ubicados los sujetos convocados y a quién se invita realmente con lo que parece una forma de señalamiento desvalorizante.

Este tipo de mensajes tal vez permita entender por qué las mujeres de la Asociación siempre se negaron a realizar actividades de alfabetización en el espacio de la escuela, en opinión de la presidenta "...en la escuela les da vergüenza, por eso si la alfabetización la hacemos allí no va a funcionar, no van a ir, se sienten mal".

La contundencia de éstas y tantas otras distancias no debe ocultar la constante búsqueda de numerosos actores escolares de formas de encuentro con las familias y organizaciones del barrio, el intento de encontrar lugares y flexibilizar posiciones, en definitiva, el hecho de que estos encuentros y desencuentros se construyen y redefinen cotidianamente en una lógica plagada de tensiones y de límites, pero también de voluntades inclusoras que suponemos tal vez permitan ir construyendo otra imagen de la escuela y otras formas de relación y definiciones de sujeto. Volvamos a las imágenes incluidas y advirtamos lo que puede implicar en un sistema que se ha 
estructurado sobre un discurso nacionalista en alta medida xenofóbico - sobre todo hacia la migración latinoamericana-, la pintura de la bandera boliviana en la puerta del edificio escolar. Multiplicar imágenes que invoquen, que inviten, que recuperen significados ausentes y palabras silenciadas, sigue siendo necesario para construir puentes que permitan imaginar un tránsito posible. De no existir estos puentes, la continuidad cultural no podrá ser imaginada en situaciones como ésta... más que fuera de la escuela.

¿Cómo se posicionan las familias y organizaciones migrantes de Escobar frente a la escuela? Recurrentemente los sujetos con los que conversamos expresan su preocupación por la insuficiencia de servicios de guardería en el barrio, la discontinuidad en los estudios de nivel medio, el alto analfabetismo entre los adultos. La falta de continuidad en el nivel secundario y mucho más en el universitario suele asociarse a la complejidad y discontinuidad que se produciría en el pasaje de situaciones escolares en contextos locales - la escuela primaria del barrio "donde estamos nosotros", "la mayoría son hijos de paisanos"- a la escuela secundaria, —ya no en el barrio sino en muchos casos en el centro de Escobar- donde "los tratan mal", los chicos "sí sufren" y en muchos casos terminan abandonando. Con respecto a la escuela primaria más cercana a la colectividad, la primera respuesta en general suele ser "la escuela está bien" "como mayormente están los hijos de bolivianos, a mí me parece bien"18.

Sin embargo, luego de estas evaluaciones positivas y de tono formal se señalan cuestiones como la falta de trabajo de la escuela sobre los estilos comunicativos particulares, la ausencia de referencias a festividades de las localidades que corresponden a la población del barrio, y sobre todo, la referencia añorada a las formas escolares más disciplinadas en Bolivia — cuestiones estas últimas extensivas a la escuela de la ruta-.

Las relaciones con la escuela, en definitiva, alternan entre el deseo de inclusión - aludido por ejemplo en la preocupación porque los niños hablen bien el castellano, consigan una vacante en la escuela más prestigiosa de la ruta, realicen trayectorias escolares largas, tengan un título, se desenvuelvan "acá"-, la denuncia — más o menos silenciosa - de situaciones de discriminación, los reclamos y la desconfianza mutuos. Se advierten además situaciones de confrontación no siempre explícita entre las imágenes de infancia y de sujeto desde las cuales comprender las expectativas puestas en la escolaridad.

En este punto retomamos más específicamente la reflexión sobre las tensiones identitarias en la localidad, concibiendo a la escuela como un espacio más donde se manifiesta la apuesta de familias y organizaciones por la continuidad y la experiencia de la discontinuidad en las relaciones intergeneracionales.

Para abordar las continuidades y distancias en las imágenes de infancia, una entrada posible se asocia a la fuerte presencia entre muchos adultos migrantes de

${ }^{18}$ Esta valoración ha llamado nuestra atención considerando una serie de problemas más o menos evidentes de la escuela como la alta rotación del equipo directivo, problemas edilicios como la existencia de un pozo ciego en el patio de la escuela que desborda regularmente, la suspensión de clases cuando llueve por problemas de electricidad, etc. 
la imagen de un sujeto niño ideal — "los niños bolivianos"- como obediente y siempre dispuesto responder a las órdenes adultas: "Si yo lo mando a mi hijo a la escuela es para que aprenda ambas cosas, el respeto y el estudio" (migrante boliviano, participante activo en la Asociación de mujeres). Esto aparece en alguna medida condensado en una implícita, y en algunas ocasiones explícita, demanda disciplinadora hacia las escuelas del barrio, asociada como mencionamos recién a relatos nostálgicos de la propia escolaridad en Bolivia ("más ordenada", "se dan más contenidos", "es más estricta"), y en ocasiones a referencias a prácticas escolares vinculadas a la copia y la prolijidad aparentemente legitimadas en Bolivia y que no serían replicables con la misma centralidad en Argentina donde "todo trabajan con recortes, agarran una revistita y ya está".

El seguimiento del proyecto de creación de una escuela "propia" "que tenga lo boliviano y también lo argentino", "que los maestros sean paisanos" 19, da cuenta de la dificultad para concretar instancias que articulen expectativas y demandas de la población migrante con el sistema educativo; en definitiva, remite a una historia con fuerte presencia de proyectos educativos paralelos a la educación estatal en Bolivia, habla de la compleja vinculación de las organizaciones sociales con el Estado, de las preocupaciones por el presente y también de las apuestas a futuro. El tema fue planteado en numerosas asambleas de socios de la colectividad pero al día de hoy sigue sin resolverse. Uno de los interesados en el proyecto recuerda así la última asamblea de la Colectividad donde se trató el tema:

El estado se ofreció a pagar los sueldos docentes y todo lo que era mantenimiento en una escuela que funcionaría en terrenos de la colectividad y que nosotros pudiéramos elegir a los maestros, por ahí un docente paisano, o conocido de la zona. No todos pensamos lo mismo, pero los de la colectividad no quisieron (se refiere a los representantes de la Colectividad), ellos querían un colegio privado, todavía tienen en mente eso, que dependa solo de la colectividad, yo creo que eso no se puede. Dijeron que en un futuro... el día de mañana del gobierno, nos van a sacar el lugar... va a pasar a ser del gobierno, que nosotros no vamos a poder meter nada, por ahí se puede hacer una promesa que no se va a cumplir, entonces por ese miedo... dijeron que no... y así paso" (miembro de la Colectividad Boliviana y colaborador de la Asociación de Mujeres, 2012).

\section{Reflexiones finales: los dilemas identitarios entre las familias y la escuela en contextos de diversidad y desigualdad}

La dinámica de la localidad - y en esto no parece una excepción con relación a otros espacios que parecen funcionar en cierta medida como "enclaves" de grupos migrantes subalternizados - responde a la vez a condicionantes estructurales - asociados a la situación del país de origen y de destino, la marginación territorial, las situaciones de discriminación y la reivindicación de derechos- y a las particularidades locales — origen rural de muchos adultos migrantes, asociación a la

${ }^{19}$ Vale aclarar que la discusión de este proyecto se dio juntamente con la construcción de un barrio cerrado al lado de la colectividad (el barrio "Cerro Rico") que como dijimos fue loteado mayormente entre población boliviana. 
producción hortícola y el comercio, existencia de organizaciones de gran capacidad e impacto y nucleamiento-. Tanto los condicionantes globales como las lógicas locales aparecen atravesados simultáneamente por dimensiones de clase, de género y de generación articuladas con procesos de identificación que se explicitan en clave étnica y nacional.

Hemos intentado mostrar cómo en la lógica local se despliega la preocupación de los adultos por la transmisión de referencias identitarias a las nuevas generaciones y los dilemas de los niños y jóvenes, en tanto sujetos donde confluyen expectativas familiares - en gran medida asociadas al mantenimiento de la identificación con Bolivia - y escolares — frecuentemente vinculadas a imágenes devaluadas de este país-.

Las expectativas formativas familiares, los encuentros y desencuentros con la escuela aparecen de esta forma signados por la tensión entre la proyección de continuidad en la identidad de las nuevas generaciones, la percepción de una profunda discontinuidad en la transmisión intergeneracional, los proyectos de inclusión a la nueva sociedad y los permanentes cambios en la localidad. Vale resaltar que se trata de proyecciones de inclusión en situaciones de evidente exclusión social y educativa, como así también de apuestas por la continuidad identitaria en situaciones de profundos cambios.

Es necesario preguntarnos ¿si la identidad remite a cierta constancia, a la ilusión de la permanencia?, qué pasa en situaciones definidas por la transformación y la discontinuidad no solo determinadas por la migración, sino también por los cambios en el nuevo espacio y las transformaciones que experimentan las distintas generaciones? Pero además, debemos atender a los sentidos que adquieren estas tensiones identitarias en situaciones de tan evidente desigualdad. En el contexto de una población discriminada en la sociedad de destino, las identificaciones nacionales pueden ser un elemento de fortalecimiento y resistencia, pero a su vez, considerando que se trata de una población profundamente fragmentada y cuyas condiciones de vida son muy heterogéneas, también puede resultar funcional al encubrimiento de los conflictos internos de intereses y posiciones. Estas cuestiones sin duda están presentes en las relaciones entre adultos y jóvenes tanto en espacios familiares como escolares.

¿Qué lugar asume la escuela en esta situación? ¿Qué sentidos adquiere la escolaridad atravesada por estos dilemas entre la continuidad y el cambio, entre el deseo de inclusión y las múltiples formas de experimentar la desigualdad y la exclusión?

Es necesario detenerse en las potencialidades y también en los riesgos de iniciativas que se presentan como alternativas, como la creación de "una escuela propia". Debemos tener en cuenta las consecuencias de polarización de propuestas a las que siempre están expuestas las experiencias educativas en contextos de diversidad y desigualdad. Sabemos que este tipo de iniciativas puede resultar tanto en proyectos de autonomización de dispositivos de imposición del Estado en la formación de las jóvenes generaciones, como en procesos de guetización y fragmentación.

En el trabajo registramos que junto con propuestas alternativas a la escuela oficial, se realizan reclamos a esta última que en principio podríamos calificar como tradicionales: disciplinamiento, dictado de más contenidos, etc. En el contexto de 
una localidad articulada complejamente con el Estado nacional, con la memoria presente del país de origen y que experimenta situaciones de profunda ruptura y discontinuidad en la transmisión intergeneracional, es necesario comprender lo que implica la demanda de una escuela más disciplinadora y el hecho de que algunas de las prácticas escolares valoradas por las familias y organizaciones puedan ser definidas como tradicionales. Más que calificar estas demandas en relación a un supuesto paradigma más moderno que caracterizaría el sistema educativo argentino, - cuestión por demás discutible tanto a nivel de la normativa como de las situaciones escolares concretas- las mismas deben ser comprendidas con relación a los modelos de sujeto y de socialización en tensión. Parecieran estar señalando un posicionamiento de la población migrante con relación a la educación como espacio de continuidad cultural y de transmisión de las referencias nacionales a las nuevas generaciones (Novaro, 2012, 2013). No podemos dejar de advertir que los discursos que legitiman esta continuidad y la vigencia de estas tradiciones se explicitan reforzando la supuesta homogeneidad de un colectivo que construye lazos comunitarios en una situación en muchos sentidos adversa y reconoce en su interior relaciones de desigualad - de clase, de género y generacionales - y poder evidentes.

En definitiva, estos dilemas e iniciativas deben ser entendidos tanto por quienes nos dedicamos a la investigación como por quienes definen formas de intervención publica, ubicándolos en un contexto sumamente crítico que implica modos particulares de imaginar los sujetos y proyectar el futuro. Posiblemente estas situaciones, retomando viejos debates educativos, deban ser analizadas poniendo tanta o más atención en los modelos de identificación y socialización en tensión, que en el grado de actualización de las formas de relación, los mecanismos de instrucción y los modelos pedagógicos propuestos.

Resulta significativo en este contexto que si bien se señalan los quiebres con la escuela, la continuidad del colectivo se exprese de parte de los adultos migrantes de forma articulada con lo que la escuela representa - incluso con la expectativa puesta en formas escolares "propias".

La situación analizada muestra la relevancia de comprometernos en la discusión de los modelos de sujeto, transmisión, saberes y memorias que el sistema educativo legitima, junto con la necesidad de evitar la deslegitimación a priori de otras imágenes y paradigmas. La actualidad de estos debates es evidente considerando que la normativa vigente en el sistema educativo argentino (en consonancia con muchos países de la región) exalta el respeto a la diversidad cultural y el reconocimiento del papel educativo de las familias y reconoce el desafío de pensar a la vez lo común y lo particular (Ley de Educación 26206).

Por último, una alusión a las voces de los niños y jóvenes, solo relativamente presentes en este texto. Más o además de lo que sus familias y docentes esperan, ellos son actores activos en el tránsito y la resolución de estos dilemas. Solo a modo de hipótesis finalizamos con la siguiente reflexión que esperamos nos oriente en futuras indagaciones más centradas en su perspectiva; en situaciones donde pareciera que los niños y jóvenes no terminan de ser asociados claramente ni a lo argentino ni a "lo boliviano", al tiempo que en alguna medida se espera que se asocien a ambos, 
es necesario preguntarnos si estas tensiones implican en ellos sentimientos de desarraigo y crisis identitarias, o los habilitan en su misma historia como portadores de una experiencia donde la referencia nacional se vive menos natural y fijamente que en otras situaciones; a partir de allí es también válido preguntarnos si estos niños y jóvenes se encontrarían particularmente habilitados para poner en cuestión el carácter definitivo y excluyente con el que en general se imponen las identificaciones nacionales, aportando desde sus vivencias y posiciones a construir nuevas formas de experimentar las identidades.

\section{Referencias bibliográficas}

BENENCIA, Roberto (Coord.)

1997 Arrea hortícola bonaerense. Cambios en la producción y su incidencia en los actores sociales. Buenos Aires: La Colmena.

BENENCIA, Roberto

2008 "Migrantes bolivianos en la periferia de ciudades argentinas: procesos y mecanismos tendientes a la conformación de territorios productivos y mercados de trabajo", en S. Novick, (Comp.), Las migraciones en América Latina. Políticas, culturas y estrategias. Buenos Aires: Catálogos.

CAGGIANO, Sergio

2005 "Lo nacional y lo cultural. Centro de Estudiantes y Residentes Bolivianos: representación, identidad y hegemonía" en E. Doménech (Comp.) Migraciones contemporáneas y diversidad cultural en la Argentina. Córdoba: Editorial Centro de Estudios Avanzados, Universidad Nacional de Córdoba, 155-186.

CANDAU, Joël

2008 Memoria e identidad. Buenos Aires Ediciones del Sol: Serie antropológica.

CERRUTTI, Marcela

2009 "Diagnóstico de las poblaciones de inmigrantes en la Argentina", Buenos Aires, Serie de Documentos de la Dirección Nacional de Población, Secretaría de Interior, Ministerio del Interior, Organización Internacional para las Migraciones, Marzo.

DIEZ, María Laura; NOVARO, Gabriela

2014 "Continuidades y discontinuidades entre sistemas educativos nacionales: la educación en Bolivia y en Argentina desde una perspectiva intercultural" En Alicia Villa; María Elena Martínez (comps.) Relaciones escolares y diferencias culturales: la educación en erspectiva intercultural. Buenos Aires Centro de Publicaciones Educativas y Material Didáctico, (Ensayos experiencias).

DOMENECH, Eduardo

2007 "La agenda política de las migraciones en América del Sur: el caso Argentina", en Revue Européenne des Migrations Internationales (REMi), vol 23 (1): 71-94.

DREIDEMIE, Patricia

2011 "Nosotros lo hablamos mezclado. Estudio etnolingüístico del quechua hablado por migrantes bolivianos en Buenos Aires". Colección Tesis, Universidad Nacional de Río Negro, Argentina. 
DREIDEMIE, Patricia; ROMANI, Carla

2007 "Migrantes bolivianos hablantes del quechua en Escobar", ponencia presentada en "Lanzamiento de la Red Nacional de Investigadores sobre discriminación". Buenos Aires, Inadi, Diciembre de 2007.

GARCIA, Daniel

2008 “Y Mamma Ocllo enseñó a las mujeres el arte del tejido” Monografía final para el Seminario de Pueblos Originarios. Maestría en Antropología, FLACSO, Buenos Aires.

GARCÍA, Castaño; ÁLVAREZ VEINGUER, Aurora; RUBIO GÓMEZ, María

2011 "Prismas trans-escolares en el estudio de las migraciones". Revista de Antropología Social 20: 203-228.

GAVAZZO, Natalia

2011 "Acceso diferencial a la ciudad. Identificaciones y estereotipos entre los hijos de inmigrantes bolivianos y paraguayos en Buenos Aires" Social and Spatial Inclusion of International Migrants. Paper Series, 8. Disponible en: http://www.unescochairiuav.it.

2012 Hijos de bolivianos y paraguayos en el área metropolitana de Buenos Aires. Identificaciones y participación entre la discriminación y el reconocimiento. Tesis doctoral. Facultad de Filosofía y Letras. Universidad de Buenos Aires.

GONZÁLEZ GUARDIOLA, Lola

2000 De Bartolina Sisa al comité de receptoras de alimentos de El Alto: antropología del género y organizaciones de mujeres en Bolivia. Universidad de Castilla La Mancha.

GRIMSON, Alejandro

1999 Relatos de la diferencia y la igualdad. Los bolivianos en Buenos Aires. Buenos Aires. Eudeba.

HOBSBAWM, Eric

1999 "Inventando tradiciones". Revista Bitarte, 18: 39-53.

LAVE, Jean; WENGER, Etienne

2007 Situated Learning: Legitimate peripheral participation. Cambridge University Press: Cambridge.

MANHEIN, Karl

1993 "El problema de las generaciones" Revista Española de Investigaciones Sociológicas, 62: 193-244.

NOVARO, Gabriela

2011 "Niños migrantes y escuela: ¿identidades y saberes en disputa?", en G. Novaro (Coord.), La interculturalidad en debate. Experiencias formativas y procesos de identificación en niños indigenas y migrantes, Buenos Aires: Editorial Biblos, 179-203.

2013 "Migración y Educación. Procesos de inclusión y exclusión educativa de niños migrantes”, en G. Karasik (Coord.), Migraciones internacionales. Estudios y reflexiones sobre la movilidad territorial contemporánea, CICCUS. 
NOVARO, Gabriela; DIEZ, María Laura

2012 “Una inclusión silenciosa o las sutiles formas de la discriminación? Reflexiones a propósito de la escolarización de niños bolivianos", en C. Courtis y M. I. Pacecca (Comps.), Discriminaciones étnicas y nacionales: un diagnóstico participativo. Buenos Aires: Editores del Puerto y Asociación por los Derechos Civiles, 37-57.

NOVICK, Susana; MERA, Carolina

2008 "Migraciones y políticas en Argentina. Tres leyes para un país extenso", en S. Novick (Comp.) Las migraciones en América Latina. Políticas, culturas y estrategias. Buenos Aires: Catálogos.

ORTIZ, Claudia

2005 "Proyectos político-culturales de las organizaciones de inmigrados: estrategias para la territorializacion del desarraigo", en E, Doménech (Comp), Migraciones contemporáneas y diversidad cultural en la Argentina. Córdoba: Editorial Centro de Estudios Avanzados, Universidad Nacional de Córdoba, 187-201.

PACECCA María Inés; COURTIS, Corina

2008 “Inmigración contemporánea en Argentina: Dinámicas y políticas”. Serie Población y Desarrollo, 84.

PACECCA, María Ines; COURTIS, Corina (Comps.)

2011 Discriminaciones étnicas y nacionales: un diagnóstico participativo. Buenos Aires, Editores del Puerto y Asociación por los Derechos Civiles.

PINTO, José

2008 Bolivia nos obligó a viajar. Situación de las Mujeres Bolivianas inmigrantes en Argentina. La Paz: Interaccion y desarrollo - Consejería en proyectos.

PIZARRO, Cynthia

2007 "Inmigración y discriminación en el lugar de trabajo. El caso del mercado frutihortícola de la colectividad boliviana de Escobar". Revista Estudios Migratorios Latinoamericanos, 21(63): 211-244.

POLLAK, Michael

1989 "Memoria, olvido, silencio". Revista Estudios Históricos. Rio de Janeiro, 2(3): 3-15.

RIVERA, Silvia

2004 "La noción de derecho o las paradojas de la modernidad poscolonial: indígenas y mujeres en Bolivia”. Revista Aportes Andinos, 11.

SASSONE Susana MARÍA; MERA Carolina

2007 Barrios de migrantes en Buenos Aires: Identidad, cultura y cohesión socioterritorial. Actas V Congreso Europeo CEISAL de latinoamericanistas -Consejo Europeo de Investigaciones Sociales de América Latina-Las relaciones triangulares entre Europa y las Américas en el siglo XXI: expectativas y desafíos -Universidad Libre de Bruselas-Universidad Católica de Lovaina. 